\section{CME Palliative medicine}

\author{
Edited by Fiona Hicks
}

Consultant in palliative medicine, Leeds Teaching Hospitals NHS Trust

and senior clinical lead for end-of-life care, Yorkshire and the Humber SHA

\title{
Advance care planning
}

Suzanne Kite, consultant in palliative medicine, Leeds Teaching Hospitals NHS Trust, Leeds General Infirmary

Advance care planning (ACP) is a process of discussion about future care between an individual, their care providers and often those close to them. It provides a framework for patients to inform decision making should they lose capacity. ${ }^{1}$ ACP spans the documentation of conversations that happen as a part of good end-of-life care between patient and healthcare team regarding treatment preferences, goals and location of care, through to formal, legally binding advance decisions.

There are excellent national guidelines on ACP, ${ }^{1,2}$ although significant effort will be required to implement them. Annually, $1 \%$ of the UK population dies, with only $15 \%$ dying suddenly. ${ }^{3}$ Most people wish to die at home, yet over half will die in hospital. Ever greater medical interventions available to manage advanced, progressive disease broaden the options, and therefore decisions that patients and doctors must make.

\section{The End-of-Life Care Strategy}

The End-of-Life Care Strategy (DH 2008) recognises that quality and choice in end-of-life care are far from equitable and sets out an ambitious, far-reaching agenda to address this (Table 1). ${ }^{4} \mathrm{ACP}$ is a key element within this, with the aim of fulfilling goals held by many patients including: ${ }^{4,5}$

- participation in decisions about treatment preferences
- preparation for death

- achieving a sense of completion

- being in familiar surroundings in the company of close family and friends.

\section{Palliative care provision}

Most care is delivered by primary and/or secondary care teams who are not specialists in palliative care. Initiatives, such as the Gold Standards Framework $^{6}$ and Liverpool Care Pathway for the dying, ${ }^{7}$ have been implemented to support care in these settings (Table 2). The need for all health professionals to have skills in assessment, symptom management, communication and ACP for the end of life is now recognised ${ }^{4}$ and is reflected in undergraduate curricula.

Specialist palliative care (SPC) is available for patients with complex needs (physical, psychological, social or spiritual) which cannot be met by their usual teams. Referral requires patient consent - hence discussion about the palliative nature of treatment. SPC services are available on the basis of need, rather than diagnosis, and include inpatient units (such as hospices), community and hospital advisory teams, daycare and outpatients.

\section{Starting the conversation}

The role of the physician in ACP is established, but much remains to be learned in the key skills of prognostication, communication, goal setting and documentation (Table 3).

\section{Table 1. The main strands of the end-of-life strategy. 4}

1 Promotion of public awareness and reducing taboos about death and dying

2 An integrated approach to planning, contracting and monitoring service delivery across health and social care as part of a strategic approach to commissioning

3 Identification of people approaching the end of life to be strengthened. NHS staff to have communication skills training so that they are equipped and confident in initiating conversations and supporting people approaching the end of life

$4 \quad$ All people approaching the end of life and their carers should have their needs assessed and have a care plan which records their preferences, including where they would wish to die

5 Ensure that care is well coordinated and can be accessed rapidly 24/7. Aim to avoid unnecessary emergency admissions to hospital:

- local registers for people approaching the end of life

- health and social care working together

6 Support the provision of high quality, integrated care across all settings: hospitals, community, care homes, sheltered and extra-care housing, hospices and ambulance services

7 Ensure that health and social care staff provide sensitive and culturally and spiritually responsive care during the last days of life and after death

8 Ensure health and social care organisations provide readily available information on all local services for those approaching the end of life

9 The needs of carers and families should be recognised, using a formal 'carers care plan' where appropriate

10 End-of-life care training should be commissioned and provided to ensure that relevant staff have the necessary competences

Research and data collection analysis are needed to underpin the above. 


\section{Prognostication}

Prognostication is difficult, even with well-defined disease trajectories, such as in many cancers and motor neurone disease (MND). It is even harder in progressive disease with a relapsing and remitting course, such as chronic heart failure and obstructive pulmonary disease. The question 'Would I be surprised if my patient died in the next 12 months?'8 can help identify those with whom to start the conversation about end-of-life care. Other possible triggers include:

- a new diagnosis of a life-limiting condition

- a deterioration in prognostic markers

- a step change in treatment

- multiple hospital admissions
- admission to a care home, or

- whenever a thorough reassessment of the patient's needs is required. ${ }^{2}$

Within specialties, experienced physicians will usually be able to characterise a set of clinical features representing the onset of end-stage disease which can be used to guide decision making.

\section{Communication}

Doctors may feel nervous about starting the conversation and patients may be waiting for the doctor to initiate this. There are perceived and real barriers to communication on both sides and facilitatory factors can be hard to achieve organisationally (Table 4). Many fear that addressing end of life will take away hope, and an approach of 'hoping for the

\section{Table 2. Tools to support end-of-life care.}

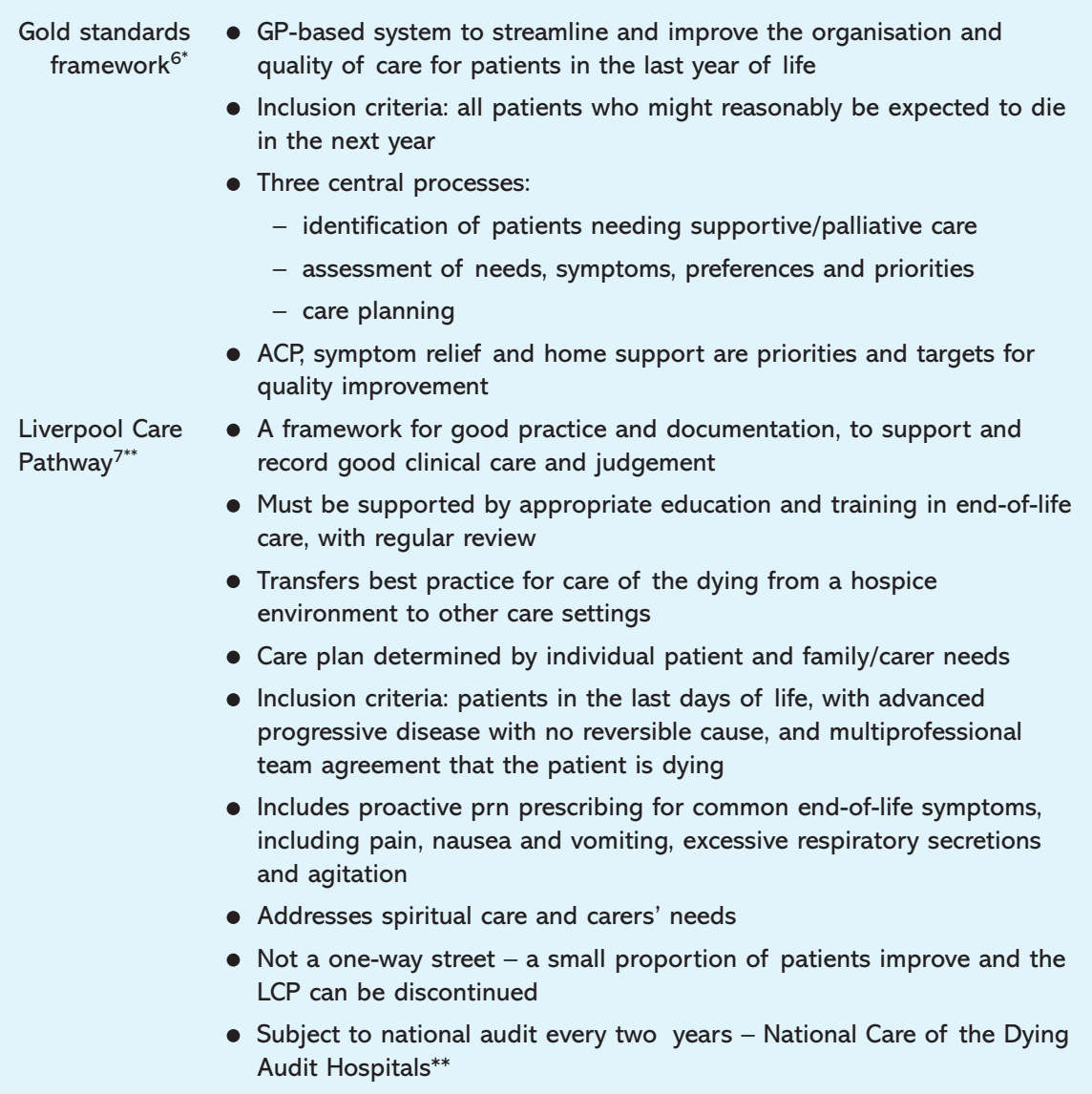

"Further information available at www.goldstandardsframework.nhs.uk

${ }^{* *}$ Further information and current version of the LCP available at www.mcpcil.org.uk $\mathrm{ACP}=$ advance care planning; GP = general practitioner; LCP = Liverpool Care Pathway; prn $=$ as required. best, preparing for the worst' can be useful.

Engagement in discussion will be determined by the degree of patient insight that death is near. For some patients, this will prove impossible while others will welcome the opportunity. Patients may wish to discuss some aspects of care but not others. Patients may initiate discussion themselves. The question 'How long have I got?' provides an opportunity to discuss progress and expectations and to set realistic goals, even if a precise answer is impossible and often inappropriate.

The most effective ACP is achieved when patient and physician work collaboratively. For this, preferred styles of decision making and information exchange need to be aligned. Clinicians have been found to underestimate patients' desire for information and discussion but to overestimate patients' desire to make decisions. ${ }^{9}$ Informed ACP requires the doctor to know the medical facts, treatment options and the local resources and services available, and to communicate them effectively to the patient. Patients may choose a supportive or palliative care approach if this is presented to them as a positive choice.

ACP is best viewed as a process, with time between discussions for reflection and clarification of questions. Conversations may continue with other healthcare professionals. Once bad news has been absorbed, concerns can be elicited and addressed, and individual priorities, preferences and goals identified. The patient

\section{Table 3. Communication with the patient.}

'I think that the best physician is the one who has the providence to tell the patient according to his knowledge of the present situation, what has happened before, and what is going to happen in the future.' Hippocrates (470-410 BC)

'I must say that when my Mum was in hospital the doctors don't give you a lot of information at all. My Mum was in 10 days. I never knew what was wrong with her. I'm not one for asking questions but I used to say "What's wrong with her? No one ever came up to me to say "Oh, your Mum's got this or your Mum's got that". On the death certificate, it's got 'heart failure'. ${ }^{13}$ 
must feel in control of the timing, place and pace of discussion with the option to stop at any time.

\section{Documentation}

Documentation of discussions is essential. Currently, most patients are content with recording a verbal statement but a minority may wish to draw up a formal legal document. ${ }^{1}$

\section{Legal framework}

The Mental Capacity Act (MCA) 2005 ${ }^{10}$ provides the framework for decision making when patients lack capacity - a common consideration in end-of-life care. Doctors are expected to be conversant with the act ${ }^{10}$ and the Code of Practice. ${ }^{11}$ The legal status of advance statements and decisions, and the role and responsibilities of lasting powers of attorney are clearly explained.

\section{Advance statement}

An advance statement is a general statement regarding wishes, preferences, beliefs and goals that an individual makes in order to clarify decision making should they lose capacity in the future. For example, 'When my MND progresses such that I need increasing admissions and my ability to communicate is limited, I would like the emphasis to be on comfort care at home rather than on lifesustaining medical interventions'. Another example is the Preferred Priorities for Care document. ${ }^{12}$ While not legally binding, such statements must inform best interests decisions.

\section{Advance decision to refuse treatment}

An advance decision to refuse treatment (ADRT) states what a patient does not want to happen to them and must relate to a specific treatment and a specific circumstance. An ADRT comes into force when the patient loses capacity to consent to or refuse treatment. It is legally binding if constituted according to the conditions in the MCA and if it meets the specific clinical circumstances. An ADRT for life-

Table 4. Barriers and facilitators to end-of-life care communication. ${ }^{14-17}$

Barriers
- Difficult subject matter
- Perception that the doctor does not want to and/or have time for discussion
- The doctor does not have time for discussion
- Fear of removing hope, causing alarm and distress
- Emphasis on a curative model of care
- Unfamiliar faces
- Multiple healthcare teams
- Unpredictability of illness
- Inadequate communication skills of professionals
- Delirium/confusion/fatigue/breathlessness
- High incidence of depression
- Language barrier and ambiguities
- Patient experience of family/friends who have died
- Physician expertise in relevant specialty
- Patient feeling cared for as a person
- Doctor asks about end-of-life care skilfully
- Patient had discussed end-of-life care with others previously
- Patient experience of being very ill
- Health system that expects doctors to have end-of-life discussions
with patients

\section{Sharing information}

ACPs need to be accessible at the point of care, reviewed regularly and up to date. Up to a third of those with formal ACPs will change them over time due to evolving circumstances. ${ }^{1}$

Healthcare professionals also need to communicate with one another on the progress of discussions.

Patients are responsible for keeping and presenting formal ACPs. Ideally, there should also be a local repository for information, accessible to all healthcare providers and including emergency services. Locality palliative care registers are advocated to hold key patient data, note of advance decisions and preferred priorities of care. ${ }^{4}$ Various models are being piloted.

\section{Conclusions}

Many patients welcome open discussion of end-of-life issues at a time, place and pace suited to them, with the potential for their preferences and priorities to be 


\section{Key Points}

Hospital physicians, with their specialist knowledge of the course and timescales of
advanced progressive disease, have a vital role to play in end-of-life care
planning
Advance care planning (ACP) is a voluntary process whereby patients can express
their preferences and goals for future care should they lose capacity
ACP is most effective when it develops collaboratively between patient and
healthcare team, and is reviewed regularly in light of changing circumstances
Tools to support ACP are available and may or may not be used. However, they
cannot replace open, honest, timely and sensitive discussion and sound clinical
judgement
ACP may be a general statement of wishes and preferences regarding the direction
and location of care and/or decisions regarding refusal/s of specific medical
interventions (eg cardiopulmonary resuscitation, ventilation and artificial
nutrition)

KEY WORDS: advance care planning, end of life, palliative care, physician-patient communication, quality of dying

identified and realised. The choice of others not to engage in this process must be respected.

All patients known to be dying should have a care plan in place. Some patients will also wish to record advance statements or draw up a formal ADRT. The skills and sensitivities required in ACP are subtle and complex, and training, experience and fine tuning are required. The current strategic focus on ACP is welcomed, but ACP must not become a tick box exercise in a target-oriented culture.

Hospital physicians have a vital role in identifying patients who have reached the last year of life, in initiating discussion and in communicating with the primary care team. As a voluntary process which progresses at the patient's pace, it is likely that ACP will need to be supported in both primary and secondary care. Processes to support this collaboration between patient, carer and healthcare teams need to be developed and training in ACP made available.

\section{References}

1 Royal College of Physicians. Advance care planning. National guideline. London: RCP, 2009.

2 NHS End of life Care Programme. Advance care planning: a guide for health and social care staff. London: NHS, 2007. www.endoflifecareforadults.nhs.uk/eolc/acp.htm

3 Lunney JR, Lynn J, Foley DJ, Lipson S, Guralnik JM. Patterns of functional decline at the end of life. JAMA 2003;289:2387-92.

4 Department of Health. End of Life Care Strategy. London: DH, 2008.

5 Steinhauser KE, Christakis NA, Clipp EC et al. Factors considered important at the end of life by patients, family, physicians, and other care providers. JAMA 2000;284:2476-82.

6 www.goldstandardsframework.nhs.uk

7 www.mcpcil.org.uk

8 Murray SA, Boyd K, Sheikh A. Palliative care in chronic illness. BMJ 2005;330:611-2.

9 Robinson A, Thomson R. Variability in patient preferences for participating in medical decision making: implication for the use of decision support tools. Qual Health Care 2001;10(Suppl 1):i34-8.

10 Mental Capacity Act 2005. www.opsi.gov.uk/ acts/acts2005

11 Department for Constitutional Affairs. Code of Practice Mental Capacity Act (2005). London: TSO, 2007.

12 www.endoflifecare.nhs.uk/eolc/ppc.htm

13 National Audit Office. Patient and carer experiences regarding end of life care in England. Leeds: Ove Arup \& Partners Ltd, 2008, 26. www.nao.org.uk/publications/0708/end_of_life_care.aspx

14 Knauft E, Nielsen EL, Engelberg RA, Patrick DL, Curtis JR. Barriers and facilitators to end-of-life care communication for patients with COPD. Chest 2005;127:2188-96.

15 Spence A, Hasson F, Waldron M et al. Professionals delivering palliative care to people with COPD: qualitative study. Palliat Med 2009;23:126-31.

16 Rogers AE, Addington-Hall JM, Abery AJ et al. Knowledge and communication difficulties for patients with chronic heart failure: qualitative study. BMJ 2000;321:605-7.

17 Murray SA, Boyd K, Kendall M et al. Dying of lung cancer or cardiac failure: prospective qualitative interview study of patients and their carers in the community. $B M J$ 2002;325:929.

Address for correspondence:

Dr S Kite, The Leeds Teaching

Hospitals Trust, Leeds General

Infirmary, Great George Street, Leeds LS1 3EX.

Email: Suzanne.kite@leedsth.nhs.uk 